\title{
Contrasting Visions of Science in Ecological Restoration: Expert-lay Dynamics between Professional Practitioners and Volunteers
}

\begin{abstract}
Ecological restoration as a popular form of volunteer participation has been praised as an example of democratic natural resource management. However, the involvement of volunteers in projects guided by professionals does not necessarily ensure democratic knowledge exchange and production. Drawing insights from citizen science and political ecology, this paper investigates the role of science in mediating the dynamics between professional practitioners and volunteers. Using case studies of ecological restoration programs at two university arboreta in the American Midwest, this paper argues that the contrasting visions of science between professional practitioners and volunteers led to conflicts and presented challenges for the institutions to genuinely engage the public in contributing local knowledge and framing management priorities. While both groups emphasized the practical aspect of science in guiding restoration work, they differed in how they conceptualized the role of humans in restoration, work priorities, and how to apply scientific theories and methods in restoration. Moreover, at the university arboreta, science defined institutional identity and claims to scientific authority further delineated boundaries between professional practitioners and volunteers. As a result, distrust, tensions, lack of engagement, and different levels of desired public participation existed in these seemingly participatory programs. Theoretically, this paper contributes to the cross-fertilization between citizen science and political ecology by underscoring the politics of participation and the role of science (and its interpretations) in challenging expert-lay dynamics in environmental volunteering programs. Practical recommendations are included for deconstructing the expert-lay hierarchy and moving restoration toward a democratic practice.
\end{abstract}




\section{Keywords}

Ecological restoration; Public participation; Volunteers; Citizen science; Expert-lay dynamics, Political ecology

\section{Introduction}

In previous work, I argued that the practice of ecological restoration contains an inherent democratic potential. By this claim, I meant that at its best the activity of ecological restoration preserves the democratic ideal that public participation in a public activity increases the value of that activity. This value in restoration is brought out most effectively by those projects that unite local human and natural communities, and that increase the level of local participation in those restoration projects.

- Andrew Light (2000, p.163-4)

Ecological restoration involves human's intentional actions in "assisting the recovery of an ecosystem that has been degraded, damaged, or destroyed" (Society for Ecological Restoration, 2004, p.3). In contrast with traditional conservation thinking that regards humans as a negative force in destroying the environment, ecological restoration not only recognizes humans as one integral part of the ecosystem, but also grants humans a positive role in assisting nature's recovery (Higgs, 2003; Jordan, 2003; Jordan and Lubick, 2011). This recognition of the 
role of humans in influencing nature's trajectory serves as an alternative to the dualistic thinking of human-nature relationship and has gained great momentum in contemporary natural resource management (Gobster and Hull, 2000; Friederici, 2006; Egan et al., 2011; Hobbs et al., 2013).

In the opening quote, Philosopher Andrew Light argues that the practice of ecological restoration is inherently democratic because it provides opportunities for public participation and community involvement. In fact, ecological restoration has been championed by many scholars as an example of participatory environmental management, especially in the first-world, urban context (Light, 2006; Higgs, 2003; Gross, 2006; Gobster, 2010; Newman, 2011). Although, to some extent, ecological restoration projects have mobilized many local communities to care for the environment, the diverse interest each group brings presents challenges for democratic participation.

Situated at the nexus between nature and society, ecological restoration has been a topic of interest for geographical inquiries. Studies have addressed conflicts surrounding "which and whose nature to restore" with a focus on exploring the diverse social interpretations of nature among stakeholders. These cases demonstrate that different social groups, for example, governmental agencies, environmental scientists, local resource users, recreationists, and conservationists, all have different opinions on how to restore and manage ecological communities. Specific lines of contestation vary from case to case. In an urban setting, conflicts often center on recreational uses, aesthetics, and property rights (Gobster, 2001; McManus, 2006; Hagerman, 2007; Newman, 2011). In rural communities, tensions emerge from contrasting meanings of cultural landscapes, a sense of community, power struggles between environmentalists, traditional resource users, and governmental policies (Nesbitt and Weiner, 2001; Rikoon, 2006). Ecological restoration projects are especially controversial in European 
countries given the long history of interworking between nature and people and studies have addressed topics of nature-culture hybridity, nature's authenticity, and cultural ambivalence toward restoration (Eden et al., 2000; Wastfelt et al., 2012; Emery et al., 2013). In Australia and New Zealand, restoration projects also serve as cases for contesting nativeness and indigeneity among different communities (Coombes, 2007; Trigger et al., 2008). As these studies have demonstrated, there is no one single nature to restore, but rather, negotiations of "which and whose nature to restore" are constantly complicated by power dynamics among social groups, identity politics, and different ways of understanding nature-society relationships. ${ }^{1}$

Whereas these studies contribute to our understanding of the inherent controversy in ecological restoration across different interest groups, I argue that even within groups supporting restoration, there exist similar tensions and contradictions. Especially in participatory restoration programs, land managers, volunteers, and conservation groups may share common restoration objectives on a broad scale. Nevertheless, detailed examination of the interplay among these groups often reveals hidden politics of participation and power struggles, which challenges the notion of ecological restoration as a democratic practice.

Specifically, this study investigates the interactions between professional practitioners and experienced volunteers at two university arboreta in the American Midwest. ${ }^{2}$ Although both professional practitioners and volunteers were supportive of restoration, their opinions diverged

\footnotetext{
${ }^{1}$ In addition to the most relevant studies reviewed here, other lines of geographical inquiry focus on ecological restoration as a case for analyzing changing narratives of environmental policies (see Clark, 2009; Norgaard et al., 2009) and neoliberal governance of the environment (see Robertson, 2010; Dempsey and Robertson, 2012). Others also examine stream restoration as an example of a new form of expertise, which is produced in the private sector as opposed to in the academia (see Doyle et al., 2013; Lave 2012, 2014).

${ }^{2}$ For the purpose of highlighting the expert-lay dynamics in ecological restoration, the categories of "professional practitioners" and "volunteers" are used in this paper. However, both groups encompass a wide variety of people. Generally, professional practitioners have formal training in ecology and are in charge of making decisions on land management. They have titles of land care managers, horticulturists, and research scientists. Volunteers are the general public who participate in restoration programs at the arboreta. This study focuses on "experienced volunteers," who participate regularly and have longer-term commitment to restoration projects.
} 
on issues of the role of humans in restoration and how to implement restoration projects on the ground. Through my research, the role of "science" (and its interpretations) emerged as a critical concept in mediating the dynamics between the two groups. Whereas both groups referred to "science" in their discussion about restoration, they meant different interpretations of science. Generally volunteers referred to science broadly defined, as ecological knowledge. Although volunteers rarely used the term "science" directly, they frequently made references to ecological concepts behind restoration. Moreover, their enthusiasm about the learning aspect of restoration work was considered as a form of scientific inquiry. By contrast, professional practitioners conceptualized "science" narrowly as academic research and scientifically-informed practices. Claims to scientific authority were often made by professional practitioners to delineate their boundaries against "lay" volunteers. ${ }^{3}$ As a result, although both groups seemingly worked collaboratively for restoration projects, there were tensions and contradictions therein.

In this paper, I first review debates over the role of science in ecological restoration. To address gaps in current studies of environmental volunteering, I draw insights from citizen science and political ecology and argue how the two fields can not only inform each other, but also shed light on the dynamics between conservation professionals and volunteers. I then analyze the contrasting visions of science between professional practitioners and volunteers through case studies. The paper concludes with theoretical contributions and practical applications for environmental volunteering programs.

\section{Debates over the role of science in ecological restoration}

Since the emergence of ecological restoration in the 1970s, science has been a strong component. The early practitioners of restoration argued that ecological restoration is the

\footnotetext{
${ }^{3}$ Such an emphasis on scientific authority is characteristic of professional practitioners at the university arboreta. It is important to note that professional practitioners at other organizations, such as environmental NGOs, city parks, and community groups, may not emphasize scientific authority as much.
} 
ultimate test of ecological theories - if people can put damaged ecosystems back to work again that means they have really understood how ecosystems work (Bradshaw, 1987; Jordan et al., 1987). Ecological restoration exemplifies the mutually enhancing relationship between science and practice. On the one hand, restoration ecology as science lays out the scientific foundation for the practice. On the other hand, ecological restoration as practice examines scientific theories and poses new research questions.

As the field expands in scope, the central role of science has become more prominent. Many ecologists and environmental scientists emphasize the importance of basing restoration work on ecological theories and methods and warn against conventional trial-and-error approaches to restoration (Pickett and Parker, 1994; Lake, 2001; Falk et al., 2006). This emphasis on the role of science has generated debates over the relative importance of other social and cultural factors in ecological restoration.

Cultural anthropologist Eric Higgs $(1994,2005)$ argues that science is one, but not the only, component of ecological restoration. Cultural practices, aesthetic preferences, social needs, and other political and economic considerations should also be taken into account. Higgs worries that the hierarchy of knowledge constructed by singling out science over other knowledges would limit the scope of restoration and risk losing restoration's social relevance.

Both Higgs and Light further expand their idea of restoration as restoring humans' relationships with nature to conceptualizing restoration as a democratic practice (Light and Higgs, 1996; Higgs, 1997, 2003; Light, 2000, 2006). When ecological restoration is framed as community-based projects, people from all walks of life are welcomed to participate. Based on this democratic thesis, they argue against the domination of scientific knowledge over other knowledges of nature. Instead of conducting restoration as scientific endeavors, they regard 
restoration as providing opportunities for the public to engage in democratic discussion about how to restore ecological communities and participate in the restoration processes.

Critiques of the scientific dominance are also raised by ecologists and environmental scientists who emphasize the interdisciplinary essence of ecological restoration (Hobbs, 2004; Turner, 2005; Cabin, 2007; Weiher, 2007; Suding, 2011; Murcia and Aronson, 2014). They realize that restoration projects are embedded in broader social and political contexts. Is the public supportive of restoration? What are the existing resource uses that are in conflict with restoration goals? What are the implicit political agendas of a restoration project? These are questions outside the domain of science, but critical to the success of restoration projects.

Similarly, there are also discussions about the relative roles of science and value/art of restoration (van Diggelen et al., 2001; Davis and Slobodkin, 2004; Winterhalder et al., 2004). Although these restoration scientists recognize the importance of social value in restoration, their conceptual separation of science from value/art is not only dualistic but also uncritically present science as a value-free endeavor. ${ }^{4}$

These debates suggest that the role of science is critical in the discussion of ecological restoration as a democratic practice. ${ }^{5}$ Whereas most restoration scientists emphasize the importance of basing restoration work on scientific theories and methods, many argue for a more participatory approach that integrates diverse perspectives. Nevertheless, most studies of the

\footnotetext{
${ }^{4}$ Whereas many STS scholars have long argued that science (and scientists, scientific knowledge, and scientific methods) is socially constructed, value-laden, partial, and situated (Merton, 1973; Latour and Woolgar, 1986; Pickering, 1992, Harding, 1998; Haraway, 1999; Knorr-Cetina, 1999; Law, 2004), in debates over the relative importance of ecological/environmental science and other social/cultural/political/economic considerations in ecological restoration, science is often presented as value-free and decontextualized from the social environment. This framing not only reinformces scientific authority but also presents the two parts as incompatible (see Gross, 2002; Higgs, 2005).

${ }^{5}$ Such debates over the role of science and other considerations in environmental affairs parallel similar discussion in public policy and planning (Hajer, 1993; Schneider and Ingram, 1993; Feldman et al., 2006, McBeth et al., 2010; Knox, 2013) and stream rehabilitation programs (Gooch, 2004; Hillman and Brierley, 2005; Spink et al., 2010; Kohlhagen et al., 2013).
} 
participatory aspect of restoration naively portray ecological restoration as a communal endeavor without addressing the contrasting visions and power dynamics among participants.

Environmental volunteering as one form of public participation, especially, has been presented as a win-win strategy to benefit both environmental organizations and the general public while the politics of participation therein have often been ignored. It is to this politics of participation that citizen science and political ecology can greatly contribute insights. The next section reviews the two fields and lays out the groundwork for analyzing my case studies.

\section{How can citizen science and political ecology inform studies of environmental volunteering?}

Environmental volunteering has gained great interest in the United States and worldwide in recent decades (Propst et al., 2000). Studies of environmental volunteering have three main strands. The first explores volunteers' motivations, psychological benefits of volunteering, and resulting changes in environmental attitudes and behaviors (Miles et al., 2000; Ryan et al., 2001; Bruyere and Rappe, 2007; Measham and Barnett, 2008; Toomey and Domroese, 2013). The second analyzes the positive outcomes of volunteering, such as capacity building, community engagement, and increased environmental awareness (Gooch, 2004; Lee and Hancock, 2011; Asah and Blahna, 2012). The third uncovers challenges in managing volunteer programs, such as volunteer burnout, the lack of resources, and different expectations between organizations and volunteers (Freeman, 2004; Sharpe and Conrad, 2006; Hobbs and White, 2012).

My research built on the foundation of these different strands of the environmental volunteering literature by focusing on the interactions between professional practitioners and volunteers. I argue that questions about expert-lay dynamics (such as who decides project goals and implementation strategies, how professional practitioners and volunteers interact with each 
other, and what stages of the project allow volunteer participation) are not only critical to the success of environmental volunteering programs, but also problematize the claim of ecological restoration as a democratic practice. Specifically, I draw theories from citizen science and political ecology to shed light on the role of science in mediating the dynamics between professional practitioners and volunteers.

The field "citizen science" (as framed in science and technology studies, STS) focuses on deconstructing the hierarchy between experts and laypeople and engaging the public in contributing their diverse knowledges (Irwin, 1995; Irwin and Wynne, 1996; Kleinman, 2000; Fuller, 2006). These studies challenge the authority of science/scientists and the claim of the public as ignorant. To the contrary, studies unveil the wealth of knowledge the public has about a specific topic (e.g. natural resource management) and how expert-lay encounters are complicated by power asymmetry, identity politics, and past experience. Other studies of citizen science focus on the production of knowledge in the public domain and the broadening of expertise to include lay knowledges (Gibbons et al., 1994; Fischer, 2000; Collins and Evans, 2007; Whatmore 2009).

To date, most citizen science studies have focused on medical disputes and environmental hazards (e.g. Epstein, 1996; Irwin et al., 1996; Brown, 2000; Allen, 2003), where the public is in a subordinated position being forced to react against dominating actors, be it doctors, health care authorities, or polluting industries. I argue that similar expert-lay dynamics and struggles also exist in environmental volunteering programs. Questions on who gets to participate, what kinds of power hierarchy exist among participants, and how knowledges are shared are all central citizen-science questions that have yet been dealt with in great depths in the context of environmental volunteering.

Interestingly, the term "citizen science" has also caught the attention of conservation 
professionals, but with a very different twist from how citizen science is framed in STS. With the rationales for raising general environmental awareness, capacity building, and eliciting local ecological knowledge, many conservation projects now incorporate "citizen scientists" to help with data collection and monitoring (Brandon et al., 2003; Cooper et al., 2007; Crall et al., 2011; Connors et al., 2012). However, the main focuses of these projects are quite different from citizen science framed in STS. Citizen science monitoring projects are led by conservation professionals with main concerns on the consistency and reliability of data collected by the public. Under this framework, the public is enrolled in the existing expert-lay hierarchy of these conservation projects, rather than being engaged in contributing their knowledge and participating in decision-making processes.

Political ecology has long examined the politics of participation in the context of natural resource management, focusing on questions such as how participation is defined, what constitutes "the community," and heterogeneity within social groups (Agrawal and Gibson, 1999; Turner, 1999; Berkes, 2004; Ellis, 2011). Moreover, an increasing number of political ecologists now integrate STS concepts to examine the knowledge politics involved in environmental programs (Forsyth, 2003; Goldman et al., 2011; Fagerholm et al., 2013; Sultana, 2013; Zimmerer, 2014). Studies interrogate the role of Western science in framing environmental problems and solutions and uncover alternative understanding of environmental systems and management practices. This strand of political ecology not only brings natural resource management as a topic to the attention of citizen science, but also critically problematizes participation in environmental programs.

My study of the expert-lay dynamics in ecological restoration is situated in the nexus between citizen science and political ecology. By examining the role of science in mediating the 
dynamics between professional practitioners and volunteers, this paper presents not only a critical response to the claim of ecological restoration as a democratic practice, but also a timely addition to the environmental volunteering literature.

\section{Case study and research methods}

The research was based on my intensive case study at two university arboreta in the American Midwest from 2006 to 2008. Since my research focused on the role science plays in expert-volunteer dynamics, university arboreta were chosen as my cases given their dual missions for scientific advancement and public engagement. The Midwest not only is the birthplace of ecological restoration but also home to burgeoning interests in public participation in restoration programs. Both of my case study arboreta play an important role in promoting ecological restoration through scientific research and environmental education. Both arboreta are living laboratories for ecological research and offer classes, lectures, and tours for the public to learn about ecological restoration as well as volunteering opportunities for the public to get involved.

Generally, volunteer participation is welcomed in both university arboreta. The "workdays" are particularly popular among the general public. Most workdays are on weekend mornings and are structured as three-hour sessions. Some workdays are led by the staff (i.e. professional practitioners) and others are led by volunteer stewards. Volunteers are involved in a variety of activities, predominantly invasive species control (e.g. cutting shrubs and pulling weeds), but also seed collecting, planting, monitoring, and helping with prescribed burns. Through approximately 300 hours of participant observation, I became familiar with the restoration activities volunteers do, shared the experience volunteers gained from the work, and observed the interactions between professional practitioners and volunteers. While working 
along with volunteers, I conversed with them about their motivations and experience with

restoration and took photographs. After each event, I kept field notes recording my observations, personal reflections, and topics for discussion to be included in later focus group discussions and interviews. $^{6}$

In the second phase of my research, I conducted focus group discussions and interviews with professional practitioners (11) and volunteers (31) associated with the university arboreta (Table 1). ${ }^{7}$ Most of the professional practitioners at the two university arboreta whose duties were directly related to restoration work and/or volunteer outreach were interviewed. Volunteer participants were recruited by distributing flyers at restoration events, e-mails, and contacting volunteer stewards directly. Two focus groups with volunteers ( 5 and 8 volunteers in each) were conducted and the other participants were interviewed one-on-one or in a group of 2 to 3 people. ${ }^{8}$

Table 1

Number of research participants in each role category by arboretum

\begin{tabular}{llcc}
\hline Category & Sub-category & Arboretum A & Arboretum B \\
\hline Professional Practitioner & Land Management & 5 & 3 \\
& Public Outreach & 2 & 1 \\
\hline Volunteer & Volunteer Steward & 5 & 5 \\
& General Volunteer & 12 & 9 \\
\hline
\end{tabular}

General topics for the volunteers (in both focus group discussions and interviews) included their motivations for participating in restoration work, their ideas of nature and perceived role of humans in restoration, how the participation experience has transformed their environmental attitudes and behaviors, and their interactions with the professional practitioners.

\footnotetext{
${ }^{6}$ Having this experience as a volunteer myself was critical to my research. My regular appearance at volunteer events connected me to professional practitioners and volunteers, who were later recruited as my research participants. This experience also allowed me to formulate interview questions that my participants could relate to. 7 Whereas both "professional practitioners" and "volunteers" are heterogeneous categories, such grouping allowed my analysis to focus on the "role" people play in restoration projects. See footnote 2 for explanation of how my research participants were categorized into these two groups.

${ }^{8}$ I differentiate focus group discussion and interview based on the ways I conducted the dialogue. At focus group discussions, I posed questions for the participants to discuss among themselves. I played the role as a moderator to elicit feedback and encourage exchange of ideas. At semi-structured interviews, I prepared a list of interview questions that I asked every interviewee. At the same time interviewees were allowed to respond freely and digress. When interesting new information came up, I followed up to elicit more responses.
} 
Interview topics for the professional practitioners included their professional background and its influence on their interpretations of restoration, their experience working with volunteers, and their opinions on involving the public in restoration programs.

All focus group discussions and interviews were voice recorded and transcribed verbatim. The transcripts and field notes were then imported into NVivo 8 (QSR International, 2008) for qualitative analysis. The coding involved an iterative process of open coding, axial coding, and selective coding (after Corbin and Strauss, 2007). At first, transcripts were coded into meaning units (free nodes) and then organized into categories in a hierarchical structure (tree nodes). By the end of open coding, I generated 230 nodes nested in five categories: (a) background and interpretations of ecological restoration, (b) program organization and projects, (c) volunteer motivations and experiences, (d) interactions among actors, and (e) cross-site comparison.

Then, axial coding was applied to examine the connections between phenomena. Using positionality as a starting point of analysis, I related participants' interpretations of ecological restoration to their background, substantiated by experiences they had with restoration. Conflicts and tensions were revealed when specific incidents were mentioned and through comments made about the other group. These were then traced to the different ideas of the role of humans and science in restoration as well as institutional identity and program organization.

Finally, selective coding was applied to summarize the central phenomena of the study. Through inductive abstraction, I diagrammed the connections between core concepts and mapped out the main storyline guided by theories from citizen science and political ecology. The following section presents the result of the case study.

\section{Conflicts and tensions in participatory restoration programs}

\subsection{The role of humans and science in ecological restoration}


When asked about motivations for volunteering, many volunteers referred to their concerns for the environment in general, personal desires to contribute to society, hands-on learning, and opportunities to make friends sharing similar interest. Many of these motivations have been summarized by other studies about restoration (Miles et al., 2000; Ryan et al., 2001). One special characteristic of volunteering for ecological restoration projects is the direct personal involvement in helping the environment, as Edward, a long-time volunteer, shared his motivations for volunteering:

I always had a big issue of what I can do about the environment. How can I make change? I can be a senator, right? Or what can I do more immediately? Volunteering for restoration work is one of those of things you can do immediately, in your backyard. ${ }^{9}$

Responses from other volunteers also indicated that volunteering for ecological restoration is about bringing positive changes to the environment on a personal level. Whereas many of the environmental crises we face today are too overwhelming, volunteering for restoration projects gives people opportunities to connect with the environment personally. ${ }^{10}$

Such a sense of direct involvement and personal contribution was closely related to how volunteers perceived the role of humans in restoration. From volunteers' perspective, humans take an active role in the restoration processes. For them, restoration is not simply about restoring ecological entities and processes, but also about restoring the relationships between people and nature - a point that resonates with many scholars focusing on the social aspects of restoration (Gobster and Hull, 2000; Higgs, 2003; Jordan, 2003; Egan et al., 2011).

When asked about their ideas of nature and the role of humans in nature, volunteers

\footnotetext{
${ }^{9}$ All names used in the paper are pseudonyms. Focus group discussion, 12.17.2006.

${ }^{10}$ Focus group discussion, 12.17.2006.
} 
expressed a strong agreement on "humans being a part of nature" — not only are humans responsible for the environmental problems we face today, but our daily activities are also intimately connected to the health of the earth. Susie, a volunteer steward, summarized the group's consensus:

An important part is that we are not separated from the environment.

We're part of it. We do affect how it is and it affects us. Ecological restoration is connecting people with nature, connecting people with the earth. $^{11}$

Given that humans are a part of nature, many volunteers feel that it is our responsibility to take care of nature and ecological restoration is a great way to make this connection. Such emphases on human's participatory experience in ecological restoration presented a stark contrast to professional practitioners' perspectives, which focused on the role of science.

Professional practitioners at the two university arboreta all had formal education in ecology or environmental sciences. This background influenced their framing of ecological restoration as scientific exploration, rather than as human's connection with nature as envisioned by the volunteers. Matthew, a land manager, reflected on the importance of bridging the gap between science and practice in restoration:

We probably talk a lot about the importance of bridging the gap between restoration on the ground and restoration as science. I think for restoration to go forward as a science [...] that gap has to be bridged. Science has to be a big part of that process. ${ }^{12}$

This emphasis on the role of science in restoration was repeatedly mentioned by other

\footnotetext{
${ }^{11}$ Focus group discussion, 12.17.2006.

${ }^{12}$ Interview, 7.16.2008.
} 
professional practitioners in my interviews, but was seldom mentioned by the volunteers.

Professional practitioners' conceptualization of ecological restoration as a synergy between science and practice resonated with comments made in the broader field of restoration (Jordan et al., 1987; Pickett and Parker, 1994; Falk et al., 2006).

Professional practitioners' interpretations of ecological restoration and the role of humans in the process were highlighted in the interview with Scott, a land manager. Scott commented that he viewed the arboretum as an intellectual enterprise for scientific experimentation and regretted that the public only looked at it as a park for recreation:

I think there're two ways of looking at the arboretum. One is a physical place and the other one is as an idea. We do research and try to learn how to restore ecosystem. We see the arboretum as an intellectual enterprise, as an idea. I think a lot of people just view the arboretum as a place, a nice place to come and take a walk. People constantly refer to it as the "arboretum" rather than as an experiment. I don't see the arboretum is valued by the majority of the people as I value it. ${ }^{13}$

Scott stressed the critical role of the arboretum as a research institution. This notion of restoration as a scientific endeavor was further underscored by Scott's response to the question of the role of humans in restoration:

I see myself as a problem solver. Well, I mean, restoration is a real physical and intellectual challenge. I think my main goal in restoration is to try to $[\ldots]$ help the ecosystems to heal themselves and try to restore

\footnotetext{
${ }^{13}$ Interview, 12.18.2007. Interestingly, when sharing his view of the role of the university arboretum in advancing scientific understanding of restoration, Scott contrasted his viewpoint to that of the general public. Throughout my research, it was not uncommon to find different social groups referring to "the other" group when commenting on their own positions. This issue of trust and imaging the other will be discussed in section 5.4
} 
ecosystem functions, structures, and processes that they can use to help them survive into the future. ${ }^{14}$

Scott's responses were revealing in that he regarded ecological restoration as scientific exploration and himself as a problem solver aiming to figure out how ecosystems work. Although humans still play a role in assisting ecosystem recovery, the focus was on scientific exploration rather than on establishing reciprocal relationship between humans and nature as volunteers envisioned their roles in restoration.

Overall, there were fundamental differences in how volunteers and professional practitioners interpreted the role of humans and science in ecological restoration. Volunteers interpreted restoration as connecting humans and nature and as personal contribution to helping the environment. By contrast, professional practitioners defined ecological restoration as scientific endeavors and viewed humans as observers and experimenters of ecosystems. As studies of political ecology have suggested, conflicts and tensions usually occur when social groups have different interpretations of nature-human relationships.

\subsection{Tangible results versus invisible ecological processes}

One of the main tensions between the two groups is the issue of tangible results versus invisible ecological processes. Volunteers enjoyed the opportunity to get directly involved in restoration work, which not only provided a great sense of accomplishment, but also made them feel that they were making real immediate impacts. By contrast, professional practitioners often looked beyond immediate actions and planned for long-term management of the site.

Much of the restoration work that involved volunteers, for example, pulling weeds and cutting invasive shrubs, provided stark visual before-and-after contrasts. Seeing these tangible differences contributed to a strong sense of accomplishment and motivated continuing

\footnotetext{
${ }^{14}$ Interview, 12.18.2007.
} 
volunteering, as volunteer Burt shared his exhilaration after clearing out invasive shrubs at a workday:

I guess ecological restoration is an act of being unselfish. I like giving, being able to give in a tangible way. Be able to see the effects of what I did in a positive way. Like yesterday, we cleared out this whole corner of honeysuckles and buckthorns and we finally saw what it should be. Wow! We did a lot! I enjoyed that for the rest of the day. ${ }^{15}$

Similarly, volunteer Edward likened restoration work to personal investment: "When you work directly in something you actually invest your own sweat and effort into it." ${ }^{\text {16 }}$ This physical connection to the work and the resulting visual differences were often mentioned by volunteers as a major factor driving continuing participation.

Invasive species control is the main activity involving volunteers in restoration, not only because it is labor intensive, but also because it requires little training. More importantly, it provides the aforementioned tangible results that contribute to volunteers' sense of accomplishment. However, many professional practitioners expressed concerns for volunteers' enthusiasm for "killing the bad plants," as Christine commented on an elderly lady who liked to uproot a whole invasive shrub:

This is how she does honeysuckle. She just yanks them down because they're kind of short rooted. She'll rock on that thing. And it's hard to get her not to do that. I don't like doing that because it does soil disturbance. It's bare and weeds get in and you're just promoting another problem. So I

\footnotetext{
${ }^{15}$ Focus group discussion, 12.17.2006. Honeysuckles and buckthorns are common invasive species in my study areas.

${ }^{16}$ Focus group discussion, 12.17.2006.
} 
much rather cut and herbicide. And we do herbicide very judicially and we do it ecologically. ${ }^{17}$

Whereas uprooting a whole plant created immediate tangible results, its side effect on soil disturbance was often invisible to volunteers. Moreover, it usually took another year to see the sprouting of new invasive plants as a result of soil disturbance. Nevertheless, the transient nature of volunteer participation gave volunteers little opportunity to appreciate the fact that restoration work takes a long time to progress.

By contrast, professional practitioners were aware of the limitation of cutting and uprooting alone on controlling invasive plants. The cut stumps need herbicide treatment, followed up with prescribed burns, multiple years' shrub control, and revegetation. These are the longer-term, invisible processes that are critical to the success of restoration projects, but are less often communicated to and experienced by volunteers.

Volunteers, nevertheless, were not to be blamed for being short-sighted either given that most of the volunteer work only involved invasive species control. Volunteers seldom had the chance to participate in the follow-up procedures, such as planting and monitoring. Consequently, novice volunteers could easily get the impression that restoration is only about "removing plants that do not belong." ${ }^{18}$ Whereas professional practitioners were aware of the ecological complexity involved in different stages of restoration, volunteers' limited experience often narrowed their understanding of restoration to removing invasive species.

Overall, driven by the desire to contribute personally to the environment, volunteers enjoyed the direct physical involvement in restoration work and they favored work that led to

\footnotetext{
${ }^{17}$ Interview, 1.15.2008.

${ }^{18}$ Gobster (2005) and Larson (2005) have addressed the counterproductive effects of the war metaphors of invasive species in ecological restoration. Nevertheless I found this phenomenon rather common in my study, especially for the general volunteers who lacked basic understanding of ecological restoration.
} 
immediate tangible differences. By contrast, professional practitioners had a broader view and looked beyond the immediate and planned for longer-term processes. Moreover, professional practitioners took a more distant position by taking the role of an observer in exploring factors that influence restoration outcomes. ${ }^{19}$ Such differences also led to different interpretations of ecological restoration as practical science.

\subsection{Practical science: diverging interpretations}

Both professional practitioners and volunteers cared about the practical aspect of restoration work. However, they differed in how they reacted to a new problem observed on the ground. Whereas professional practitioners would take this as an opportunity to explore the ecological processes leading to the problem and to scientifically test different restoration techniques, volunteers would like to tackle the problem immediately. For example, during my research, an invasive weed was spreading into the restored prairies at one of the arboreta, creating imminent threats. Volunteers were eager to begin manually pulling the weeds, but were prohibited by the professional practitioners because they wanted to use this as a learning opportunity to experiment with different treatment methods. ${ }^{20}$ This became a contentious issue and underscored the power hierarchy between professional practitioners and volunteers

Whereas both groups referred to restoration as "practical science," they had different interpretations. For professional practitioners, ecological sciences and theories provide the guiding principles for restoration work. In practice, practitioners apply scientific methods to test ecological theories with multiple replicated plots. The idea behind this "adaptive restoration" framework is to design restoration projects as experiments and use alternative treatments to test ecological theories. The advantage of this model is that projects can achieve management goals

\footnotetext{
${ }^{19}$ Similar contrasts on the tangibility of science have been discussed in the STS literature regarding reproductive medicine (Price, 1999), air quality monitoring (Ottinger, 2010), and biodiversity conservation (Harrison et al., 1998). ${ }^{20}$ Interviews, 6.27.2008, 10.29.2008; field notes, 5.3.2008, 6.7.2008.
} 
and gain ecological knowledge at the same time (Zedler and Callaway, 2003).

From practitioners' perspective, adaptive restoration was a perfect example of practical science. For volunteer, nevertheless, they interpreted "adaptive" as a lack of consistency, as Annie commented on her frustration on receiving different management guidelines for dealing with the same issue on the ground:

Because it's adaptive restoration, management guidelines are constantly changing. You know, one wanted to do one way, and the next season it will be a different way handling the same issue. ${ }^{21}$

Whereas professional practitioners would argue that there are a lot of unknowns in restoration and that adaptive strategies present opportunities for scientific discovery, volunteers viewed this lack of consistency as a sign of management failure.

The academic identity of the university arboreta and the prioritization of scientific research over practical work further contributed to volunteers' antipathy toward "science." Even though volunteers expressed interest in learning about ecology and the science behind restoration, they often reacted negatively when asked about scientific research at the arboreta.

Timothy, a volunteer steward, shared his frustration on having to help with research projects rather than doing "real" restoration work at volunteer workdays:

We had a few workdays where people helped clean up research plots. It's really somebody's research and I think the volunteers are frustrated with that sort of thing. And the stewards can be frustrated to see that it's more academic research rather than practical application. ${ }^{22}$

Annie, another volunteer steward at the same interview, also agreed that most people volunteer

\footnotetext{
${ }^{21}$ Interview, 10.29.2008.

${ }^{22}$ Interview, 10.29.2008.
} 
because they want to see their work as contributing to the greater good of society, rather than just for research projects. ${ }^{23}$

Whereas many volunteers are interested in the scientific aspect of restoration, their conceptualization of science is broadly defined as ecological knowledge, curiosity-driven inquiries, and based on field observation. For volunteers, ecological restoration is practical science because it operates in real-world contexts. By contrast, professional practitioners also regarded ecological restoration as practical science, but emphasized the use of scientific methods to test restoration techniques. Moreover, the slow pace of scientific research and the prioritization of experimentation over management actions often frustrated volunteers, who thus regard scientific research as "unpractical."

Even staff working in the outreach sector of the university arboreta shared similar concerns for research. They felt that research priorities often paralyzed the real work that needed to be done and joked that what the research did find were facts already well known. ${ }^{24}$ Once again, this anecdote demonstrated that when different people used the same term, in this case, "practical science" and "research," they had different ideas about what these meant. Oftentimes, for volunteers, science and research were indicative of academic authority, abstract, theoretical, and unpractical. The role of science as a claim to authority and the boundary-making and stereotyping of "the other" group further complicated the relationships between volunteers and professional practitioners.

\subsection{Trust: imagining the other}

Whereas some volunteers were unsatisfied with the prioritization of research over ground work and thought of professional practitioners as too scientifically minded and unpractical,

\footnotetext{
${ }^{23}$ Interview, 10.29.2008.

${ }^{24}$ Interview, 6.27.2008.
} 
professional practitioners also expressed reservation on volunteer work. Professional practitioners generally expressed stereotypical images of volunteers as myopic and acting too impetuously in the field with little care for long-term ecological consequences. Due to the logistical challenges in managing volunteers, ${ }^{25}$ many professional practitioners candidly commented that they had to treat volunteers as laborers and let them focus on low-skill, laborintensive types of work. ${ }^{26}$ As professional practitioners were expressing concerns for volunteer work, they overlooked a small number of experienced volunteers who had strong interest in restoration and whose involvement could benefit restoration projects at the arboreta. However, the hierarchical structure under which the two groups interacted hindered such involvement.

Such unequal power relationship not only led to professional practitioners' distrust of volunteer work, but also volunteers' discontent with the "authority." Below is a conversation between two experienced volunteers at a focus group discussion. Edward shared his urge to tackle problems on the ground immediately and his discontent with restrictions set by the professional practitioners:

Edward: I don't want to be a steward because I want to be a little bit naughty. Like when we cleared that fire lane there. I went deeper because there are some bur oaks that needed to be de-shaded and I overstepped the guideline and I went deeper.

Mary: The staff is very angry.

Edward: I think the issue was that the staff has to come back down to earth.

They need to come and visit volunteers at workdays and say, "hey this is what we were doing." Or at least tell me what your restrictions are, and

\footnotetext{
${ }^{25}$ For example, unpredictability of volunteer attendance and skill levels and high turnover rates.

${ }^{26}$ Interviews, 12.18.2007, 1.15.2008, 9.18.2008.
} 
why you are mad because of me doing this. At the very least, I would have a better understanding of your reasons for not allowing me to go deeper to clear around the oak. Because to me, when I see a problem, I just want to address them immediately. ${ }^{27}$

In this conservation, Edward expressed a desire to discuss with the professional practitioners directly to understand their reasons for specific work guidelines. However, the lack of communication and the power hierarchy between professional practitioners and volunteers reinforced the image of the professional practitioners as the hard-to-reach authority.

The concept "boundary-work" by STS scholar Thomas Gieryn $(1983,1999)$ is helpful in parsing out this tension of "othering." Gieryn argues that the boundary of science is being guarded by scientists (whose credentials are socially constructed) who constantly (re)define what is within the realm of science against what is left out. Boundary-work not only creates dualistic division of science versus non-science, but also demarcates authority. The exercise of boundarywork is especially intense in ecological science given the gray area between theoretical ecology and practical ecology. As the result, many studies found that ecologists are particularly wary of defining their boundary against advocacy groups and reinforcing their authority (Kinchy and Kleinman, 2003; Bocking, 2006; Eden et al., 2006).

Similar boundary-work was at play between volunteers and professional practitioners in my study. On the one hand, professional practitioners demarcated their boundary against the public based on their authority and expertise. On the other hand, experienced volunteers also labeled their work as "practical application," as opposed to "unpractical" scientific research. Whereas professional practitioners often expressed concerns about the quality of volunteer work, experienced volunteers regarded practitioners' insistence on scientific guidelines as unpractical.

\footnotetext{
${ }^{27}$ Focus group discussion, 12.17.2006.
} 
As a result, there were serious trust issues between the two groups in these seemingly participatory programs.

\subsection{Questions of authority and volunteer autonomy}

The identity of the university arboreta as academic research institutions strongly influenced not only how restoration work was conducted, but also how the public was involved in the programs. Questions of authority and autonomy further complicated the dynamics between professional practitioners and volunteers.

At the university arboreta, communication was mostly unidirectional—volunteer stewards received guidelines from professional practitioners and then they instructed general volunteers on what to do at public workdays. Sometimes stewards were in an awkward position because they might not agree with what they were told to do, but still had to follow work instructions. In one instance, a steward was expecting to work on pulling garlic mustards because it was their fruiting season (if the chance to pull was missed, the plants would shed thousands of seeds into the soil), but was instructed to work on other tasks that were not that sensitive to timing. ${ }^{28}$ Such frustration of not having more authority in making decisions sometimes discouraged stewards from getting more involved.

In addition to the lack of communication, there were also tensions over the how much responsibilities volunteers could have. At one of the arboreta, there was reservation on delegating more autonomy to volunteers. This arboretum rejected the adopt-a-plot program and wanted volunteers to identify with the arboretum as a whole, rather than developing special interest in the adopted areas. They worried that with the adopt-a-plot program, certain groups might develop a strong sense of ownership and demand more influence on management as Samantha, a land manager, commented:

\footnotetext{
${ }^{28}$ Interview, 5.29.2008. Garlic mustard is a common invasive weed in my study area.
} 
There were some discussions about doing adopt-a-plot with the garden.

And I have really come to completely not do that because in that situation we tend to get a group wanting more, to dictate. I mean, it's almost too much a sense of what an area needs to be. ${ }^{29}$

Whereas the staff had concerns for delegating certain groups too much responsibility on specific areas, volunteer stewards often felt disempowered when they were restricted from doing what they thought was important, as Timothy, a volunteer steward, shared a story of how one steward quit because the arboretum no longer allowed volunteers do independent work:

Several years ago if you wanted to come in and work by yourself as a steward and just have sort of an area, you can do that. And the arboretum changed that. They don't want you to work up there unless you're leading a volunteer group. There was one other steward who was doing a lot of work by himself. I think one of the reasons he stopped working there was because they wouldn't let him work by himself anymore. ${ }^{30}$

In situations like this, if there were opportunities for the steward and the professional practitioners to communicate directly on their ideas, tensions could be minimized. Moreover, new ideas about management strategies could also be raised when the two groups share their experiences and thoughts. However, the hierarchical structure of the arboreta and the distrust of each other prevented genuine communication from happening.

The above discussion highlighted a dilemma between the additional care provided by volunteer stewards and professional practitioners concerns about volunteers having too much autonomy, which might potentially endanger institutional identity. Questions of authority and

\footnotetext{
${ }^{29}$ Interview, 6.27.2008.

${ }^{30}$ Interview, 5.29.2008.
} 
autonomy created an uneasy relationship between volunteers and professional practitioners at the arboreta.

\section{Refocusing on the politics of participation and the role of science in studies of environmental volunteering}

Overall, the arboreta's identity as academic research institutions framed professional practitioners' interpretations of ecological restoration as scientific endeavors, in which the focus was on restoring ecological elements and processes guided by scientific principles. This focus on the "work" and professional practitioners' authoritative status delineated their boundaries against volunteers, who regarded restoration as personal contribution to the environment. Experienced volunteers not only cared more about the practical aspect of restoration, but also had strong desires for getting involved personally. However, the hierarchical structure under which the two groups interacted presented challenges for mutual engagement. Figure 1 summarizes main conflicts between the two groups and sources of tensions.
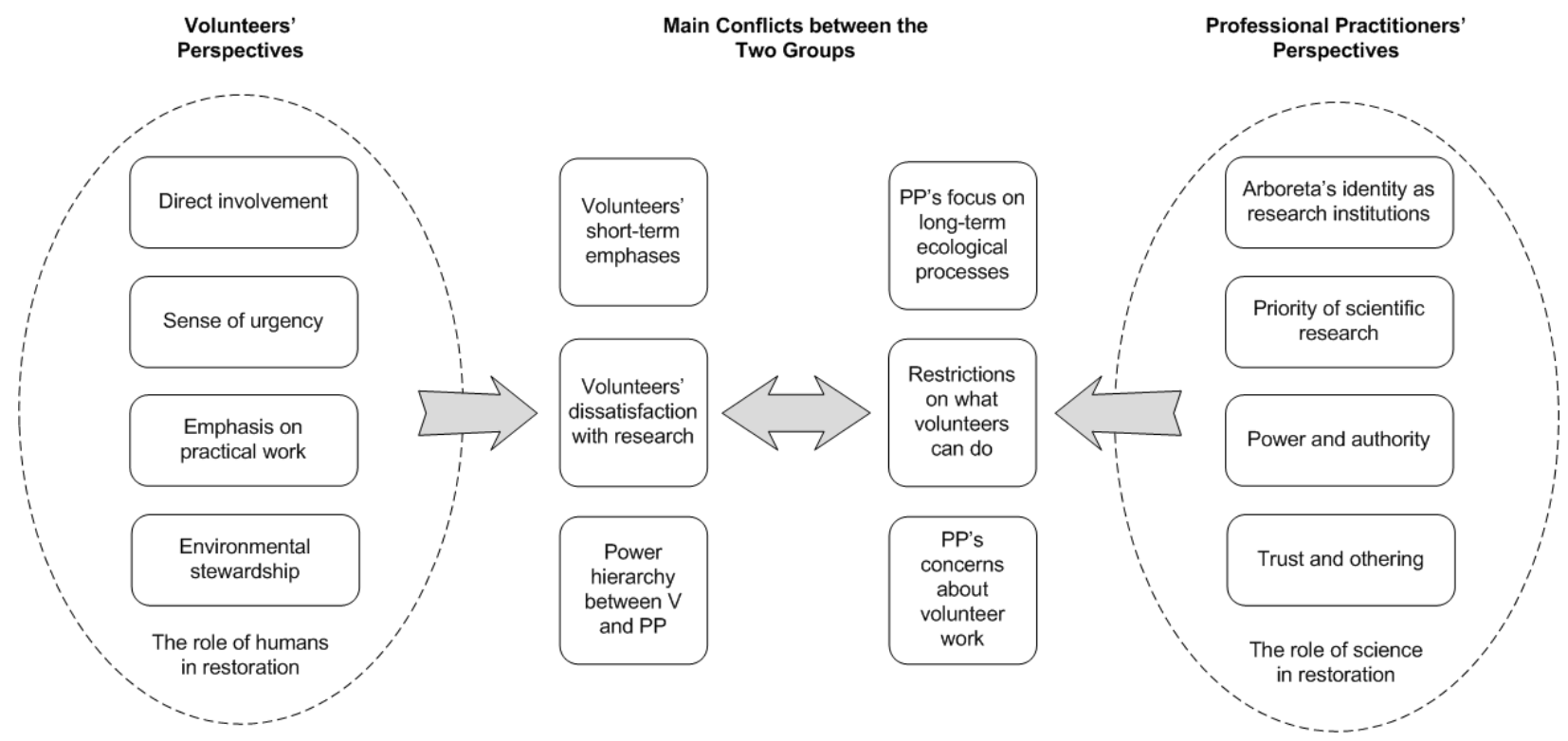

Fig. 1. Conflicts between volunteers and professional practitioners and main sources of tension. (V: Volunteers; PP: Professional Practitioners) 
Volunteers viewed ecological restoration as connecting people and nature whereas professional practitioners regarded ecological restoration as scientific endeavors. Such fundamentally different focuses contributed to their different interpretations of restoration. On the one hand, volunteers emphasized direct involvement, sense of urgency, practical work, and stewardship. On the other hand, professional practitioners emphasized arboreta's identity as research institutions and scientific research, which led to issues of authority and trust with volunteers. As the two groups interacted through restoration programs, conflicts emerged. Specifically, there were conflicts between short-term immediate actions versus long-term ecological processes, prioritization of research versus restrictions on what volunteers can do, power hierarchy between the two groups, and concerns about volunteer work.

My case demonstrated that there were internal politics between professional practitioners and volunteers in restoration programs. Particularly, different interpretations of science in restoration and the power hierarchy between groups led to tensions and conflicts. To critically address these issues, I argue that we need to refocus on the politics of participation and the role of science in studies of environmental volunteering. Nevertheless, only a few studies have interrogated this topic.

For example, Ellis and Waterton's (2005) study of volunteers in the English Nature biodiversity inventory program analyzed the network of alignment between nature, amateur naturalists, professional biologists, and conservationists in the construction of expertise and exchange of knowledges. The different imaginaries of participation, identity politics, and issues of inclusion and exclusion all led to amateur naturalists' ambivalence about the extent to which they felt comfortable contributing their expertise to the program.

Similarly, in Cornwell and Campbell's (2012) study of a sea turtle conservation project in 
North Carolina, they traced how volunteers navigated their positions between the public sphere, scientific domain, and state conservation regime. Whereas volunteers concurred with the general scientific literature, their knowledge of specific issues was informed by their locally situated observation and the pursuit of active intervention in sea turtle rehabilitation. The state's need of volunteer labor resulted in the co-production of conservation practice, but not so much the coproduction of knowledge.

As these studies and mine suggested, the involvement of volunteers in conservation programs does not necessarily ensure democratic knowledge exchange and production. Conservation science, despite its applied focus, is still largely informed by scientific theories that emphasize generalization, exploration, and experimentation. By contrast, volunteers in conservation programs are driven by strong personal interest in the particular topic (e.g. biodiversity inventory, sea turtle rehabilitation, and ecological restoration) and the desire for taking actions. The fundamentally different attitudes toward conservation along with identity politics and power dynamics present challenges for democratic knowledge exchange and production.

In studies of environmental volunteering, public participation is often portrayed as a winwin strategy for both environmental organizations and the public. Ecological restoration, especially, has been celebrated as a democratic practice. Whereas I agree that participatory restoration programs provide great opportunities for community people to come together and care for the environment, I express reservation on equating public participation with democratic practice. Many public policy scholars have argued that public participation encompasses a wide range of engagement, from low-power types of token participation to high-power types of involvement in decision-making (Arnstein, 1969; Propst et al., 2003; Stringer, et al. 2006; Head, 
2007). My study builds on this critical evaluation of public participation and focuses on the role of science as expression of authority, which hinders mutual engagement between volunteers and professional practitioners.

The fact that environmental issues often involve a variety of stakeholders with diverse interest and interpretations of human-nature relationships has long been addressed in the public policy, cultural geography, and political ecology literatures. Most of these studies are based on social constructivist theory (Schneider and Ingram, 1993; Castree and Braun, 2001; Feldman et al., 2006), critical theory (Hajer, 1993; McBeth et al., 2010; Knox, 2013), and discourse analysis (Killingsworth and Palmer, 1992; Nesbitt and Weiner, 2001; Bassett and Zueli, 2003; Rikoon, 2006). Whereas my study is founded on these theories, I specifically highlight the role of science (and its interpretations) as the sticking point of tension between professional practitioners and volunteers. Such focus addresses gaps in the existing literature in three important ways.

First, although the role of science in mediating expert-lay dynamics has been addressed by citizen science studies, existing cases focus mostly on medical disputes and environmental hazards, where the power hierarchy is steep. My study demonstrated that even in participatory restoration programs, where the public voluntarily collaborate with professional practitioners on a more equal footing, such power dynamics still exist. Second, although political ecologists have interrogated knowledge politics involved in environmental issues, their analyses focused on starkly different knowledge systems, for example, Western science versus resource users in developing countries (Forsyth, 2003; Robbins, 2003; Goodman, 2011) and traditional ecological knowledge (Nadasdy, 1999; Fernandez-Gimenez et al., 2006; von Glasenapp and Thornton, 2011). My study demonstrated that even in the first-world, urban context, among groups supportive of restoration, knowledge politics still lead to tensions. Third, studies of 
environmental volunteering have mostly focused on the positive aspects with less attention to the politics of participation. At the same time, scholars of both citizen science and political ecology have yet to take environmental volunteering as a topic for critical analysis. My study is situated at the nexus among these sets of literatures and provides a timely examination of participatory restoration programs as a democratic practice.

\section{Conclusions and practical applications}

The ideal of ecological restoration as a democratic practice bringing together diverse groups of people working for the environment, as claimed by many (e.g. Light and Higgs, 1996; Light 2000), is actually difficult to realize in practice given the diversity of people involved. My study demonstrated that even within groups supportive of restoration, power dynamics and knowledge politics still led to tensions and contradictions.

Driven by an altruistic desire to contribute to the environment, volunteers had a strong sense of urgency, sought actions that lead to tangible results, and preferred to get involved personally. By contrast, professional practitioners' background in ecology and environmental sciences framed their interpretation of restoration as scientific endeavors and they favored the role of an observer in using scientific methods to guide restoration processes. Consequently, despite both groups' emphases on the practical aspect of restoration, they differed in how they conceptualized the role of humans in restoration, work priorities, and how to apply scientific theories and methods in restoration.

As discontent and distrust between professional practitioners and volunteers intensified through time, boundary-making and stereotyping of "the other" group were also exercised. On the one hand, professional practitioners' emphases on the scientific foundation of their work not only demarcated their boundary against the public, but also led to their reluctance to engage the 
public in contributing local knowledge and framing management priorities. Long-term volunteers, on the other hand, also claimed the social relevance of their work by labeling it as "practical application," as opposed to "unpractical" scientific research. As a result, tensions and contradictions emerged on issues of authority and autonomy in these seemingly participatory programs.

Theoretically, this research contributes to studies of environmental volunteering by highlighting issues of institutional identity, power hierarchy, and social heterogeneity in complicating the expert-lay dynamics in participatory environmental projects. Whereas studies of citizen science and political ecology have long addressed these issues in other contexts, I argue that environmental volunteering as a field also warrants this critical attention. Especially as "citizen science" as a model of participatory environmental monitoring has been gaining momentum, we need to refocus on the politics of participation and the role of science to better theorize participation in this context.

Whereas my study focused on the university arboreta, with a strong emphasis on academic research, similar concerns also apply to other types of organizations. For example, forest services, municipal parks, non-profit environmental organizations, and neighborhood friends groups. Who is the expert and who is the public? What kinds of power hierarchy exist? What is the role of scientific research and public participation in restoration projects? Critically examining these questions can not only inform managers of the public's attitudes towards restoration projects, but also open up opportunities for engagement with the public.

Practically, my study suggests the following management considerations for participatory restoration programs. First, provide a variety of activities for volunteers with different interest. Whereas most restoration programs focus on the control of invasives, providing opportunities for 
other types of restoration work (e.g. seed collecting, planting, and monitoring) can not only make volunteers aware of the long-term processes involved, but also expand the framing of restoration beyond "killing the bad plants." Second, integrate environmental education with volunteer workday programs. Currently most workday programs focus solely on “tasks.” Integrating elements of environmental education (e.g. nature walk and observation) can provide the broader context for restoration and raise greater environmental awareness. Third, enhance direct communication between professional practitioners and volunteers and offer opportunities for interested volunteers to have more responsibility. Promoting direct communication can not only lessen the distrust issue, but also foster better collaboration. Moreover, for interested volunteers, organizations can offer opportunities for more involvement (e.g. site stewards, team leaders, or naturalists), so that certain volunteers can contribute their knowledge and expertise to restoration projects.

This list of recommendation points to the first step in deconstructing the expert-lay hierarchy in volunteer programs. Only by critically examining how different knowledges, values, and practices are shared and exchanged can we begin to theorize ecological restoration as a democratic practice, in which all stakeholders are engaged equally and throughout the restoration processes.

\section{References}

Agrawal, A., Gibson, C., 1999. Enchantment and Disenchantment: The Role of Community in Natural Resource Conservation. World Development 27 (4), 629-649.

Allen, B. L., 2003. Uneasy Alchemy: Citizens and Experts in Louisiana's Chemical Corridor Disputes. The MIT Press, Cambridge, MA. 
Arnstein, S. R., 1969. A Ladder of Citizen Participation. Journal of American Institute of Planners 35 (4), 216-224.

Asah, S.T., Blahna, D.J., 2012. Motivational functionalism and urban conservation stewardship: implications for volunteer involvement. Conservation Letters 5 (6), 470-477.

Bassett, T. J., Zueli, K. B., 2003. The Ivorian savanna: Global narratives and local knowledge of environmental change. In: Zimmerer, K. S., Basset, T. J. (Eds.), Political Ecology: An Integrative Approach to Geography and Environment-Development Studies. Guilford Press, New York, pp.115-136.

Berkes, F., 2004. Rethinking community-based conservation. Conservation Biology 18 (3), 621630.

Bocking, S., 2006. Nature's Experts: Science, Politics, and the Environment. Rutgers University Press, New Brunswick, NJ.

Bradshaw, A.D., 1987. Restoration: an acid test for ecology. In: Jordan, W.R., Gilpin, M.E., Aber, J.D. (Eds.), Restoration ecology: A synthetic approach to ecological research. Cambridge University Press, Cambridge, pp. 23-29.

Brandon, A., Ellis, J., Spyreas, G., Molano-Flores, B., Carroll, C., 2003. Can volunteers provide reliable data for forest vegetation surveys? Natural Areas Journal 23 (3), 254-261.

Brown, P., 2000. Popular Epidemiology and Toxic Waste Contamination: Lay and Professional Ways of Knowing. In: Kroll-Smith, S., Brown, P., Gunter, V. J. (Eds.), Illness and the Environment: A Reader in Contested Medicine. NYU Press, New York, pp. 367-383.

Bruyere, B., Rappe, S., 2007. Identifying the motivations of environmental volunteers. Journal of Environmental Planning and Management 50 (4), 503-516.

Cabin, R. J., 2007. Science-Driven Restoration: A Square Grid on a Round Earth? Restoration 
Ecology 15 (1), 1-7.

Castree, N., Braun, B. Eds., 2001. Social Nature: Theory, Practice, and Politics. Blackwell Publishing, Malden, MA.

Clark, B.T., 2009. River Restoration in the American West: Assessing Variation in the Outcomes of Policy Change. Society \& Natural Resources 22 (5), 401-416.

Collins, H., Evans, R., 2007. Rethinking Expertise. University of Chicago Press, Chicago.

Connors, J.P., Lei, S.F., Kelly, M., 2012. Citizen Science in the Age of Neogeography: Utilizing Volunteered Geographic Information for Environmental Monitoring. Annals of the Association of American Geographers 102 (6), 1267-1289.

Coombes, B., 2007. Defending community? Indigeneity, self-determination and institutional ambivalence in the restoration of Lake Whakaki. Geoforum 38 (1), 60-72.

Cooper, C.B., Dickinson, J., Phillips, T., Bonney, R., 2007. Citizen Science as a Tool for Conservation in Residential Ecosystems. Ecology and Society 12 (2), Article 11.

Corbin J., Strauss, A., 2007. Basics of Qualitative Research: Techniques and Procedures for Developing Grounded Theory, third edition. SAGE Publications, Thousand Oaks, CA.

Cornwell, M.L., Campbell, L.M., 2012. Co-producing conservation and knowledge: Citizenbased sea turtle monitoring in North Carolina, USA. Social Studies of Science 42 (1), 101-120.

Crall, A.W., Newman, G.J., Stohlgren, T.J., Holfelder, K.A., Graham, J., Waller, D.M., 2011. Assessing citizen science data quality: an invasive species case study. Conservation Letters 4 (6), 433-442.

Davis, M.A., Slobodkin, L.B., 2004. The Science and Values of Restoration Ecology. Restoration Ecology 12 (1), 1-3. 
Dempsey, J., Robertson, M.M., 2012. Ecosystem services: Tensions, impurities, and points of engagement within neoliberalism. Progress in Human Geography 36 (6), 758-779.

Doyle, M.W., Lave, R., Robertson, M.M., Ferguson, J., 2013. River Federalism. Annals of the Association of American Geographers 103 (2), 290-298.

Eden, S., Donaldson, A., Walker, G., 2006. Green groups and grey areas: scientific boundarywork, nongovernmental organisations, and environmental knowledge. Environment and Planning A 38, 1061-1076.

Eden, S., Tunstall, S.M., Tapsell, S.M., 2000. Translating nature: River restoration as natureculture. Environment and Planning D: Society and Space 18 (2), 257-273.

Egan, D., Hjerpe, E.E., Abrams, J., Higgs, E. (Eds.), 2011. Human Dimensions of Ecological Restoration: Integrating Science, Nature, and Culture. Island Press, Washington, D.C.

Ellis, R., 2011. Who's Participation? Who's Sustainability? A Critical Analysis of Initiatives for Urban Sustainability in India. Scottish Geographical Journal 127 (3), 193-208.

Ellis, R., Waterton, C., 2005. Caught between the cartographic and the ethnographic imagination: the whereabouts of amateurs, professionals, and nature in knowing biodiversity. Environment and Planning D-Society \& Space 23 (5), 673-693.

Emery, S.B., Perks, M.T., Bracken, L.J., 2013. Negotiating river restoration: The role of divergent reframing in environmental decision-making. Geoforum 47 (0), 167-177.

Epstein, S., 1996. Impure Science: AIDS, Activism, and the Politics of Knowledge. University of California Press, Berkeley, CA.

Fagerholm, N., Kayhko, N., Van Eetvelde, V., 2013. Landscape Characterization Integrating Expert and Local Spatial Knowledge of Land and Forest Resources. Environmental Management 52 (3), 660-682. 
Falk, D., Palmer, M., Zedler, J. (EDs.), 2006. Foundations of Restoration Ecology. Island Press, Washington, DC.

Feldman, M.S., Khademian, A.M., Ingram, H., Schneider, A., 2006. Ways of knowing and inclusive managmenet practices. Public Administration Review 66 (S), 89-99.

Fernandez-Gimenez, M. E., Huntington, H. P., Frost, K. J., 2006. Integration or co-optation? Traditional knowledge and science in the Alaska Beluga Whale Committee. Environmental Conservation 33 (4), pp.306-315.

Fischer, F., 2000. Citizen, Experts, and the Environment: The Politics of Local Knowedge. Duke University Press, Durham, NC.

Forsyth, T., 2003. Critical Political Ecology: The Politics of Environmental Science. New York, Routledge.

Freeman, A.N.D., 2004. Constraints to community groups monitoring plants and animals in rainforest revegetation sites on the Atherton Tablelands of far north Queensland. Ecological Management and Restoration 5 (3), 199-204.

Friederici, P., 2006. Nature's Restoration: People and Places on the Front Lines of Conservation. Island Press, Washington, D.C.

Fuller, S., 2006. The Philosophy of Science and Technology Studies. Routledge, New York.

Gibbons, M., Limoges, C., Howotny, H., Schwartzman, S., Scott, P., Trow, M., 1994. The New Production of Knowledge: The Dynamics of Science and Research in Contemporary Societies. SAGE Publications, London.

Gieryn, T., 1983. Boundary-work and the Demarcation of Science from Non-science - Strains and Interests in Professional Ideologies of Scientists. American Sociological Review 48 (6), 781-795. 
Gieryn, T., 1999. Cultural Boundaries of Science: Credibility on the Line. University of Chicago Press, Chicago.

Gobster, P.H., 2001. Visions of nature: conflict and compatibility in urban park restoration. Landscape and Urban Planning 56 (1-2), 35-51.

Gobster, P.H., 2005. Invasive Species as Ecological Threat: Is Restoration an Alternative to Fear-based Resource Management? Ecological Restoration 23 (4), 261-270.

Gobster, P.H., 2010. Introduction: Urban Ecological Restoration. Nature and Culture 5, 227-230.

Gobster, P.H., Hull, R.B. (Eds.), 2000. Restoring Nature: Perspectives from the Social Sciences and Humanities. Island Press, Washington, D.C.

Goldman, M., Nadasdy, P., Turner, M. (Eds.), 2011. Knowing Nature: Conversations at the Intersection of Political Ecology and Science Studies. University of Chicago Press, Chicago.

Gooch, M., 2004. Volunteering in catchment management groups: empowering the volunteer. Australian Geographer 35 (2), 193-208.

Goodman, M.J., 2011. The Politics of Connectivity across Human-Occupied Landscapes: Corridors near Nairobi National Park, Kenya. In: Goldman, M.J., Nadasdy, P., Turner, M.D. (Eds.), Knowing Nature: Conversations at the Intersection of Political Ecology and Science Studies. University of Chicago Press, Chicago, pp. 186-202.

Gross, M. 2002. New Natures and Old Science: Hands-on Practice and Academic Research in Ecological Restoration. Science Studies 15 (2), 17-35.

Gross, M., 2006. Beyond expertise: Ecological science and the making of socially robust restoration strategies. Journal for Nature Conservation 14, 172-179.

Hagerman, C., 2007. Shaping neighborhoods and nature: Urban political ecologies of urban waterfront transformations in Portland, Oregon. Cities 24 (4), 285-297. 
Hajer, Maarten 1993. Discourse Coalitions and the Institutionalization of Praction: The Case of Acid Rain in Britain. In: Fisher, F., Forester, J. (Eds), The Argumentative Turn in Policy Analysis and Planning. Duke University Press, Durham, pp. 43-76.

Haraway, D. J., 1999. Situated Knowledge: The Science Question in Feminism and the Privilege of Partial Perspective. In: Biagioli, M. (Ed.), The Science Studies Reader. Routledge, New York, pp. 172-188.

Harding, S., 1998. Is Science Multicultural? Postcolonialisms, feminisms and epistemologies. Indiana University Press, Bloomington, IN.

Harrison, C.M., Burgess, J., Clark, J., 1998. Discounted knowledges: farmers' and residents' understandings of nature conservation goals and policies. Journal of Environmental Management 54, 305-320.

Head, B.W., 2007. Community engagement: Participation on whose terms? Australian Journal of Political Science 42 (3), 441-454.

Higgs, E.S., 1994. Expanding the Scope of Restoration Ecology. Restoration Ecology 2 (3), 137 146.

Higgs, E.S., 1997. What is good ecological restoration? Conservation Biology 11 (2), 338-348.

Higgs, E.S., 2003. Nature by Design: People, Natural Process, and Ecological Restoration. The MIT Press, Cambridge, MA.

Higgs, E.S., 2005. The Two-Culture Problem: Ecological Restoration and the Integration of Knowledge. Restoration Ecology 13 (1), 159-164.

Hillman, M., Brierley, G., 2005. A critical review of catchment-scale stream rehabilitation programmes. Progress in Physical Geography 29 (1), 50-70.

Hobbs, R.J., 2004. Restoration ecology: the challenge of social values and expectations. Frontiers in Ecology and the Environment 2 (1), 43-48.

Hobbs, R.J., Higgs, E.S., Hall, C. (Eds.), 2013. Novel Ecosystems: Intervening in the New 
Ecological World Order. Wiley-Blackwell, West Sussex, UK.

Hobbs, S.J., White, P.C.L., 2012. Motivations and barriers in relation to community participation in biodiversity recording. Journal for Nature Conservation 20 (6), 364-373.

Irwin, A., 1995. Citizen Science: A Study of People, Expertise and Sustainabile Development. Routledge, New York.

Irwin, A., Dale, A., Smith, D., 1996. Science and Hell's kitchen: the local understanding of hazard issues. In: Irwin, A., Wynne, B. (Eds.), Misunderstanding Science?: The Public Reconstruction of Science and Technology. Cambridge University Press, Cambridge, UK, pp.47-64.

Irwin, A., Wynne, B. (Eds.), 1996. Misunderstanding Science?: The Public Reconstruction of Science and Technology. Cambridge University Press, Cambridge.

Jordan, W.R., 2003. The Sunflower Forest: Ecological Restoration and the New Communication with Nature. The University of California Press, Berkeley.

Jordan, W.R., Gilpin, M.E., Aber, J.D., 1987. Restoration ecology: ecological restoration as a technique for basic research. In: Jordan, W.R., Gilpin, M.E., Aber, J.D. (Eds.), Restoration ecology: A synthetic approach to ecological research. Cambridge University Press, Cambridge, pp. 1-21.

Jordan, W.R., Lubick, G.M., 2011. Making Nature Whole: A History of Ecological Restoration. Island Press, Washington, DC.

Killingsworth, J. Palmer, J., 1992. Esospeak: Rhetoric and Environmental Politics in America. Southern Illinois University Press, Carbondale, IL.

Kinchy, A. J., Kleinman, D. L., 2003. Organizing Credibility: Discursive and Organizational Orthodoxy on the Borders of Ecology and Politics. Social Studies of Science 33 (6), 869- 
896.

Kleinman, D.L. (Ed.), 2000. Science, Technology, and Democracy. State University of New York Press, Albany, NY.

Knorr-Cetina, K., 1999. Epistemic Cultures: How the Sciences Make Knowledge. Harvard University Press, Cambridge, MA,

Knox, C.C., 2013. Distorted Communication in the Florida Everglades: A Critical Theory Analysis of "Everglades Restoration". Journal of Environmental Policy and Planning. 15 (2), 269-284.

Kohlhagen, T., Fryirs, K., Semple, A., 2013. Highlighting the Need and Potential for Use of Interdisciplinary Science in Adaptive Environmental Management: The Case of Engandered Upland Swamps in the Blue Mountains, NSW, Australia. Geographical Research 51 (4), 439-453.

Lake, P.S., 2001. On the maturing of restoration: Linking ecological research and restoration. Ecological Management \& Restoration 2 (2), 110-115.

Larson, B., 2005. The war of the roses: demilitarizing invasion biology. Frontiers in Ecology and the Environment 3 (9), 495-500.

Latour, B., Woolgar, S., 1986. Laboratory Life: The Construction of Scientific Facts. Princeton University Press, Princenton, NJ.

Lave, R., 2012. Bridging Political Ecology and STS: A Field Analysis of the Rosgen Wars. Annals of the Association of American Geographers 102 (2), 366-382.

Lave, R., 2014. Freedom and constraint: Generative expectations in the US stream restoration field. Geoforum 52 (0), 236-244.

Law, J., 2004. After Method: Mess in Social Science Research. Routledge, New York.

Lee, M., Hancock, P., 2011. Restoration and Stewardship Volunteerism, in: Egan, D., Hjerpe, 
E.E., Abrams, J.B. (Eds.), Human Dimensions of Ecological Restoration: Integrating Science, Nature, and Culture. Island Press, Washington, DC, pp. 23-38.

Light, A., 2000. Restoration, the Value of Participation, and the Risks of Professionalization. In: Gobster, P.H., Hull, R.B. (Eds.), Restoring Nature: Perspectives from the Social Sciences and Humanities. Island Press, Washington, D.C., pp. 163-181.

Light, A., 2006. Ecological Citizenship: The Democratic Promise of Restoration, in: Platt, R. (Ed.), The Humane Metropolis: People and Nature in the Twenty-first Century City. University of Massachusetts Press, Amherst, MA, pp. 169-182.

Light, A., Higgs, E.S., 1996. The politics of ecological restoration. Environmental Ethics 18 (3), 227-247.

McBeth, M.K., Shanahan, E.A., Hathaway, P.L., Tigert, L.E., Sampson, L.J., 2010. Buffalo tales: interest group policy stories in Greater Yellostone. Political Sciences 43 (4), 391-409.

McManus, P., 2006. Mangrove battlelines: Culture/nature and ecological restoration. Australian Geographer 37 (1), 57-71.

Measham, T., Barnett, G., 2008. Environmental Volunteering: motivations, modes and outcomes. Australian Geographer 39 (4), 537-552.

Merton, R. K., 1973. The Sociology of Science: Theoretical and Empirical Investigations. University of Chicago Press, Chicago,

Miles, I., Sullivan, W.C., Kuo, F.E., 2000. Psychological benefits of volunteering for restoration projects. Ecological Restoration 18 (4), 218-227.

Murcia, C., Aronson, J., 2014. Intelligent Tinkering in Ecological Restoration. Restoration Ecology 22 (3), 279-283.

Nadasdy, P., 1999. The Politics of TEK: Power and the "Integration" of Knowledge. Arctic Anthropology 36 (1-2), 1-18. 
Nesbitt, J. T., Weiner, D., 2001. Conflicting environmental imaginaries and the politics of nature in Central Appalachia. Geoforum 32 (3), 333-349.

Nesbitt, J.T., Weiner, D., 2001. Conflicting environmental imaginaries and the politics of nature in Central Appalachia. Geoforum 32 (3), 333-349.

Newman, A., 2011. Inclusive Urban Ecological Restoration in Toronto, Canada, in: Egan, D., Hjerpe, E.E., Abrams, J.B. (Eds.), Human Dimensions of Ecological Restoration: Integrating Science, Nature, and Culture. Island Press, Wasington, DC, pp. 63-75.

Norgaard, R.B., Kallis, G., Kiparsky, M., 2009. Collectively engaging complex socio-ecological systems: re-envisioning science, governance, and the California Delta. Environmental Science \& Policy 12 (6), 644-652.

Ottinger, G., 2010. Buckets of Resistance: Standards and the Effectiveness of Citizen Science. Science Technology \& Human Values 35 (2), 244-270.

Pickering, A.,1992. Science as Practice and Culture. University of Chicago Press, Chicago.

Pickett, S.T.A., Parker, V.T., 1994. Avoiding the Old Pitfalls: Opportunities in a New Discipline. Restoration Ecology 2 (2), 75-79.

Price, F., 1996. Now you see it, now you don't: Mediating science and managing uncertainty in reproductive medicine. In: Irwin, A., Wynne, B. (Eds.), Misunderstanding Science?: The Public Reconstruction of Science and Technology. Cambridge University Press Cambridge, UK, pp. 84-106.

Propst, D. B., Jackson, D. L., McDonough, M.H., 2003. Public Participation, Volunteerism and Resource-Based Recreation Management in the U.S.: What Do Citizens Expect? Society and Leisure 26 (2), 389-415.

Propst, D.B., Wellman, J.D., Campa, H., McDonough, M.H., 2000. Citizen Participation Trends 
and their Educational Implication for Natural Resource Professionals. In: Gartner, W.C., Lime, D.W. (Eds.), Trends in Outdoor Recreation, Leisure and Tourism. CABI Publishing, New York, pp. 383-392.

QSR International Pty Ltd., 2008. NVivo qualitative data analysis software, Version 8.

Rikoon, J.S., 2006. Wild horses and the political ecology of nature restoration in the Missouri Ozarks. Geoforum 37 (2), 200-211.

Robertson, M., 2010. Performing environmental governance. Geoforum 41 (1), 7-10.

Ryan, R.L., Kaplan, R., Grese, R.E., 2001. Predicting volunteer commitment in environmental stewardship programmes. Journal of Environmental Planning and Management 44 (5), $629-648$.

Schneider, A., Ingram, H., 1993. Social Construction of Target Populations - Implication for Politics and Policy. American Political Science Review 87 (2), 334-347.

Sharpe, A., Conrad, C., 2006. Community based ecological monitoring in Nova Scotia: Challenges and opportunities. Environmental Monitoring and Assessment 113 (1-3), 395409.

Society for Ecological Restoration, 2004. The SER International Primer on Ecological Restoration, Version 2. Society for Ecological Restoration International Science \& Policy Working Group, Tucson, Arizona.

Spink, A., Hillman, M., Fryirs, K., Brierley, G., Lloyd, K., 2010. Has river rehabilitation begun? Social perspectives from the Upper Hunter catchment, New South Wales, Australia. Geoforum 41 (3), 399-409.

Stringer, L.C., Dougill, A. J., Fraser, E., Hubacek, K., Prell, C., Reed, M.S., 2006. Unpacking "participation" in the adaptive management of social ecological systems: A critical 
review. Ecology and Society 11 (2), Article 39.

Suding, K.N., 2011. Toward an Era of Restoration in Ecology: Successes, Failures, and Opportunities Ahead, in: Futuyma, D.J., Shaffer, H.B., Simberloff, D. (Eds.), Annual Review of Ecology, Evolution, and Systematics, Vol 42, pp. 465-487.

Sultana, F., 2013. Water, technology, and development: transformations of development technonatures in changing waterscapes. Environment and Planning D-Society \& Space $31(2), 337-353$.

Toomey, A.H., Domroese, M.C., 2013. Can citizen science lead to positive conservation attitudes and behaviors? Human Ecology Review 20 (1), 50-62.

Trigger, D., Mulcock, J., Gaynor, A., Toussaint, Y., 2008. Ecological restoration, cultural preferences and the negotiation of 'nativeness' in Australia. Geoforum 39 (3), 1273-1283.

Turner, M.D., 1999. No space for participation: Pastoralist narratives and the etiology of parkherder conflict in southeastern Niger. Land Degradation \& Development 10 (4), 345-363.

Turner, R.E., 2005. On the cusp of restoration: Science and society. Restoration Ecology 13 (1), $165-173$.

van Diggelen, R., Grootjans, A.P., Harris, J.A., 2001. Ecological Restoration: State of the Art or State of the Science? Restoration Ecology 9 (2), 115-118.

Von Glasenapp, M., Thornton, T.F., 2011. Traditional Ecological Knowledge of Swiss Alpine Farmers and their Resilience to Socioecological Change. Human Ecology, 39 (6), 769781.

Wastfelt, A., Saltzman, K., Berg, E.G., Dahlberg, A., 2012. Landscape care paradoxes: Swedish landscape in a European context. Geoforum 43 (6), 1171-1181.

Weiher, E., 2007. On the Status of Restoration Science: Obstacles and Opportunities. Restoration 
Ecology 15 (2), 340-343.

Whatmore, S.J., 2009. Mapping knowledge controversies: science, democracy and the redistribution of expertise. Progress in Human Geography 35 (5), 587-598.

Winterhalder, K., Clewell, A.F., Aronson, J., 2004. Values and Science in Ecological Restoration A Response to Davis and Slobodkin. Restoration Ecology 12 (1), 4-7.

Zedler, J.B., Callaway, J.C., 2003. Adaptive restoration: A strategic approach for integrating research into restoration projects. In: Rapport, D.J., Lasley, W.L., Rolston, D.E., Nielsen, N.O., Qualset, C.O., Damania, A.B. (Eds.), Managing for Healthy Ecosystems. Lewis Publishers, Boca Raton, Florida, pp. 167-174.

Zimmerer, K.S., 2014. Conserving agrobiodiversity amid global change, migration, and nontraditional livelihood networks: the dynamic uses of cultural landscape knowledge. Ecology and Society 19 (2)., Article 1. 